\title{
A Steering Wheel Angle Analysis of Old and Young Drivers in Right Turning at Intersection
}

\author{
Taebeum Ryu, Byung Chan Min \\ Department of Industrial and Management Engineering, Hanbat National University, Daejeon, 305-719
}

\begin{abstract}
Due to the ageing-related degradation in physical and cognitive abilities, the elderly have difficulty in car driving and this is related to the high rate of car accidents among them. This study investigated the kinematic characteristics of old drivers' steering in right turning at intersections by comparing with young drivers. Thirteen old(60 70) and thirteen young(20 30) drivers who participated in the experiment turned their cars right side at intersections in a driving simulator. As results, the completion time of right turning at intersection of old drivers was larger than that of young drivers. The speeds of vehicle at the beginning and ending point of the right turning area of old drivers were smaller than those of young drivers, and also the steering angle at the ending point of the turning area of the former was smaller than that of the latter. The normalized jerk of old driver's steering was significantly larger than that of young drivers. These results indicate that old drivers modify their steering movement repeatedly and take the driving strategy of avoiding risks due to their reduced physical capabilities.
\end{abstract}

Keywords: Old driver, Steering angle, Turning, Intersection, Driving simulator

\section{1. 서 론}

자동차 운전은 고령자의 독립적이고 높은 삶의 질을 유지 하기 위한 필수 조건으로 고령운전자의 수는 지속적으로 증가하고 있다. 전체 운전자 중 고령운전자의 비율은 99년 $8 \%$ 에서 2010년 21\%로 상승하고, 2020년에는 약 30\%에 달할 것으로 예측되고 있다(통계청, 2001).

고령운전자 수의 증가와 함께 고령운전자의 사고발생도 빠르게 증가하여 자동차 운전은 고령자의 생명을 위협하는 요인이 되고 있다. 1992년에 약 1,000건 이였던 고령운전 자 사고발생건수는 2005년 약 4,500건으로 약 4.5 배 증가 하였다(도로교통안전공단, 2004). 교통사고는 청년층보다 고령운전자에게 더욱 치명적이라는 점에서 문제의 심각성이 높다.

고령운전자의 교통사고는 특히 교차로에서 빈번히 발생하 는 것으로 알려져 있다. 2006 2008년간의 교통사고 통계
자료(경찰청, 2006 2008)에 따르면, 고령자의 단일로에 서의 교통사고 증가는 매년 200여 건인 반면, 고령운전자 의 교차로에서의 증가는 약 5,000 여 건으로 교차로의 교통 사고가 단일로의 교통사고보다 컸다. 또한, Mayhew et al. (2006)은 교차로에서 고령운전자들의 사고가 빈번히 발생 하며, 특히 좌회전시 사고가 발생할 비율이 높다고 하였다. 교차로 회전시 높은 사고발생율은 고령장의 인지적 저하에 주로 기인한 것으로 알려져 있다(Guerrier et al., 1995; Verhaegen et al., 1988).

이러한 고령자의 교차로 사고 특성으로 인해 고령자의 교 차로 운전 특성은 주로 좌회전시 고령자의 인지적 판단과 시각적 검색 능력 측면에서 주로 파악되고 있다. Yan et al. (2007)은 교차로 좌회전시 진입 실험에서 고령 여성운전자 는 진입할 수 있는 공간이 클 경우에 진입하는 보수적 운전 경향을 갖는다고 보고하였다. 이준범 외(2008)는 고령운전 자는 교차로 좌회전시 진입할 수 없는 상황에도 진입할 수 있다고 판단하는 경향을 보였으며, 이러한 판단의 확신 수준

Corresponding Author: Taebeum Ryu. Department of Industrial and Management Engineering, Hanbat National University, Daejeon, $305-719$. Mobile: 010-6433-2756, E-mail: tbryu@hanbat.ac.kr

Copyright@2011 by Ergonomics Society of Korea(pISSN:1229-1684 eISSN:2093-8462). All right reserved. 
도 높다고 하였다. Keskinen et al. (1998)는 고령운전자의 교차로 좌회전에 소요되는 시간이 청년층보다 크다고 보고 하였다. 또한 Bao \& Bolye(2009)은 교차로 좌회전시 고령 운전자의 시각적 주변차량 검색 능력이 저하된다고 보고하 였다.

인지적 측면에서 고령자의 교차로 운전 특성에 대한 연구 는 많으나, 운동적 측면에서 고령자의 운전 특성을 파악한 연구는 미흡한 실정이다. 고령자의 운전 특성을 운동적 측면 에서 분석한 연구로 Hong et al. (2009)는 교차로 회전에서 회전 구간의 진입 속도, 완료시간, 속도와 운전대 각도 분산 을 이용하여 주로 시간과 속도와 관련된 고령자 운전 특성 을 분석하였다. 그러나, 교차로 회전시 운동적 측면에서 고 령자의 운전 특성을 보다 심도있게 파악하기 위해서는 운 전대(steering wheel) 각도 변화의 특성을 분석할 필요가 있다.

교차로 회전시 운전대를 조절하는 운동은 도로선을 유지 하며 최종적으로 차의 방향을 바꾼다는 점에서 $\operatorname{Yan}(2000)$ 의 목적지향적 운동과 유사하다. $\operatorname{Yan}(2000)$ 은 고령자의 운 동 계획 및 수행 능력 분석을 위해 특정지점을 향한 손의 직선 및 곡선 운동 능력을 청년층과 비교하였다. 이러한 단 순 목적지향적 운동에서 고령자는 자신이 세운 운동 계획을 지속적으로 수정하였으며, 청년층보다 느리게 운동을 수행 하였다. 그러나 운전대 조정 운동은 회전 운동인 반면, Yan (2000)의 운동은 선형 운동이라는 점에서 차이가 있다. 따 라서 고령자의 단순 운동 능력 저하가 운전대 회전 운동에 서도 나타나는지 파악해볼 필요가 있다.

본 연구는 자동차 운전대 조정에 대한 고령자의 운동학적 특성을 파악하고자 진입차가 없는 교차로에서 우회전시 운 전대 조절 능력을 청년층과 비교하여 분석하고자 하였다. 본 연구는 교차로 우회전시 고령자와 청년층의 운전대의 회전 조작을 운전대의 각도 변화 데이터로 측정하였다. 그리고 운전대 조정에 따른 수행도를 비교 평가하여 고령자의 운전 대 조절 특성을 파악하였다.

\section{2. 연구 방법}

\section{1 실험참여자}

교차로 우회전 운전 실험에 고령자 13 명과 청년층 13 명 이 참여하였다. 모집된 고령운전자들은 $65 \pm 2$ 세의 남성으 로 10 년 이상의 운전 경력을 보유하고 현재 일상 생활에서 운전을 하고 있었다. 청년층은 모두 20대 남성 (23土2세)으 로 2 년 이상의 운전 경험을 보유하고 일상 생활에서 운전을 하고 있었다.

\section{2 운전 시뮬레이터}

본 실험은 세 개의 32 인치 $\mathrm{LCD}$ 모니터와 고정형 운전석 으로 구성된 운전 시뮬레이터를 이용하였다. 세 개의 LCD 모니터는 자동차 앞면과 양측면의 주행 상황을 보여주고 고 정형 운전석은 실체 차량의 운전석을 이용하여 제작되어 운 전대, 가속 페달, 브레이크 페탈, 자동기어 손잡이, 센터페시 아, 인스트루먼트 페널 등을 포함하고 있다. 또한 운전 시뮬 레이터는 운전대의 각도 변화를 센서로 측정하고 운전대 전 체 회전 각도(540도)에 대한 비율 $(\%)$ 로 저장된 텍스트 화 일을 제공한다. 운전대의 회전 각도는 우회전시는 양 $(+)$ 의 값을, 좌회전시는 음 $(-)$ 의 값으로 표시된다.

\section{3 수행 작업}

실험의 참여자들은 제작된 운전 시뮬레이터에서 교차로 우회전 운전을 수행하였다. 운전 시뮬레이터의 운전 상황은 왕복 4 차로 일반 시내의 도로 주행으로 구현되었다. 본 실 험참여자는 실험 전 구현된 시내 도로의 연습 주행을 5 분간 수행하여 운전 시뮬레이터에 익숙하도록 하였다. 실험참여자 는 시뮬레이터에 표시된 시내 주행 속도 $60 \mathrm{~km} / \mathrm{h}$ 를 준수하 면서, 평소와 같이 운전하도록 하였다(그림 1 참조). 본 실 험에서 실험참여자는 2 차로(마지막 차선) 만을 이용하여 교 차로 $1 \mathrm{~km}$ 전부터 주행을 시작하였고 교차로에서 우회전한 후 $1 \mathrm{~km}$ 를 더 주행하도록 하였다. 본 연구는 고령자 운전대 조작의 운동학적 특성을 파악하기 위해 우회전시 교차로에 접근하는 차량이 없도록 설정되었다.

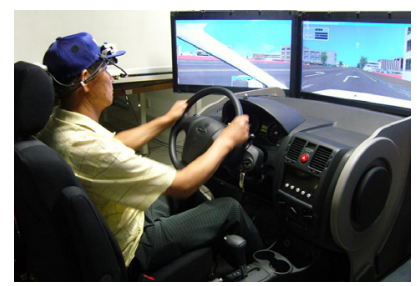

그림 1. 실험참여자의 시뮬레이터 운전 예

\section{4 우회전 구간 설정 및 분석 변수}

본 연구는 교차로에서 우회전 구간을 그림 2 와 같이 설정 하였다. 우회전하기 전 주행도로의 횡단보도 정지선를 우회 전 구간의 시작점으로, 우회전 후 만나는 횡단보도 정지선 를 우회전 구간의 완료점으로 각각 설정하였다. 그리고 운전 시뮬레이터는 이 구간 내에서 운전대의 회전 각도를 측정하 여 제공하였다. 


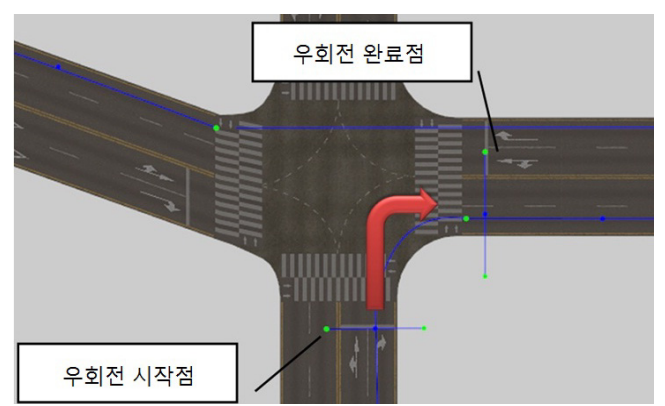

그림 2. 교차로 우회전 구간 설정

본 연구는 교차로 우회전 운전 특성을 분석하기 위해 운 전대 각도와 관련한 분석 변수들을 표 1 과 같이 정의하였다. 우선, 우회전 수행에 소요되는 시간을 비교하기 위해 우회전 완료시간이 선정되었고, 우회전 구간의 시작점과 완료점에서 의 차량 속도가 측정되었다. 운전대 회전 각도 관련 변수로 우회전 진입시와 완료시의 운전대 각도, 우회전 구간의 최대 운전대 각도, 그리고 정규화 jerk를 선정하였다. 또한, 운전 대 회전 각속도 관련 변수로 최대 운전대 회전 속도와 이의 발생 표준화 시간을 선정하였다.

표 1. 운전 조작 특성 분석 변수

\begin{tabular}{|c|c|}
\hline 변수 & 설명 \\
\hline 우회전 완료시간(sec) & $\begin{array}{l}\text { 우회전 구간 시작점부터 완료점까지 } \\
\text { 의 통과시간 }\end{array}$ \\
\hline 우회전 시작점 속도 $(\mathrm{km} / \mathrm{h})$ & 우회전 구간 시작점의 차량 속도 \\
\hline 우회전 완료점 속도 $(\mathrm{km} / \mathrm{h})$ & 우회전 구간 완료점의 차량 속도 \\
\hline 진입시 운전대 각도 $\left(^{\circ}\right)$ & 우회전 구간 시작점의 운전대 각도 \\
\hline 완료시 운전대 각도 $\left(^{\circ}\right)$ & 우회전 구간 완료점의 운전대 각도 \\
\hline $\begin{array}{l}\text { 정규화 jerk } \\
\text { (normalized jerk) }\end{array}$ & 운전대 각도 변화의 매끄러움 \\
\hline 최대 운전대 각도(ㅇ) & 우회전시 운전대 각도의 최대값 \\
\hline $\begin{array}{l}\text { 최대 운전대 회전 각속도 } \\
(\% / \mathrm{sec})\end{array}$ & 운전대 회전 속도 절대치의 최대값 \\
\hline $\begin{array}{l}\text { 최대 운전대 회전 각속도 } \\
\text { 발생 표준시간(\%) }\end{array}$ & $\begin{array}{l}\text { 운전대 회전 속도 최대값의 발생시간 } \\
\text { 을 완료시간으로 표준화한 시간 }\end{array}$ \\
\hline
\end{tabular}

동작의 jerk는 동작 가속도를 한번 더 미분한 값으로 동작 분석에 있어 동작 변화의 매끄러움(smoothness)을 분석하 는데 사용되어 왔다. 그러나 동작 jerk는 동작의 시간과 속 도가 다른 동작들을 비교하는데 적합하지 않다(Yan, 2000). 따라서 본 연구는 동작의 시간과 속도의 영향을 배제한 정 규화 jerk(normalized jerk)를 Teulings et al.(1997)의 방법에 따라 계산하였다.

\section{3. 연구 결과}

\section{1 고령과 청년운전자 차이의 분산분석 결과}

교차로 우회전시 13 명 고령운전자와 13 명 청년운전자들 의 분석 변수들에 대한 분산분석 결과는 표 2 와 같다. 총 8 개 분석 변수 중 고령운전자와 청년운전자의 차이가 유의 한 변수는 우회전 완료시간, 우회전 시작점 속도와 완료점 속도, 완료시 운전대 각도의 4 개로 나타났다.

표 2. 측정 변수들의 분산분석 결과

\begin{tabular}{l|c|c|c|c}
\hline \multicolumn{1}{c|}{ 변수 } & 고령 (SD) & 청년(SD) & $F_{(1,24)}$ & $p$ \\
\hline $\begin{array}{l}\text { 우회전 완료시간 } \\
(\mathrm{sec})\end{array}$ & $\begin{array}{c}5.5 \\
(1.2)\end{array}$ & $\begin{array}{c}3.8 \\
(1.3)\end{array}$ & 11.3 & $0.003^{*}$ \\
\hline $\begin{array}{l}\text { 우회전 시작점 속도 } \\
(\mathrm{km} / \mathrm{h})\end{array}$ & $\begin{array}{c}22.2 \\
(7.5)\end{array}$ & $\begin{array}{c}34.7 \\
(14.8)\end{array}$ & 7.5 & $0.012^{*}$ \\
\hline $\begin{array}{l}\text { 우회전 완료점 속도 } \\
(\mathrm{km} / \mathrm{h})\end{array}$ & $\begin{array}{c}23.8 \\
(5.6)\end{array}$ & $\begin{array}{c}32.2 \\
(9.1)\end{array}$ & 8.2 & $0.009^{*}$ \\
\hline 진입시 운전대 각도( $\left.{ }^{\circ}\right)$ & $\begin{array}{c}6.3 \\
(19.1)\end{array}$ & $\begin{array}{c}6.1 \\
(13.6)\end{array}$ & 0.0 & 0.983 \\
\hline 완료시 운전대 각도( $\left.{ }^{\circ}\right)$ & $\begin{array}{c}60.8 \\
(30.5)\end{array}$ & $\begin{array}{c}100.7 \\
(45.1)\end{array}$ & 6.9 & $0.014^{*}$ \\
\hline 최대 운전대 각도 $\left(^{\circ}\right)$ & $\begin{array}{c}178.8 \\
(33.5)\end{array}$ & $\begin{array}{c}166.8 \\
(29.3)\end{array}$ & 0.9 & 0.345 \\
\hline 정규화 jerk & $\begin{array}{c}237.4 \\
(235.7)\end{array}$ & $\begin{array}{c}541.1 \\
(313.9)\end{array}$ & 7.2 & $0.014^{*}$ \\
\hline 최대 운전대 \\
회전 각속도( $/ \mathrm{sec})$ & $\begin{array}{c}145.4 \\
(60.0)\end{array}$ & $\begin{array}{c}162.3 \\
(75.7)\end{array}$ & 0.4 & 0.535 \\
\hline 최대 운전대 회전 각속도 & $\begin{array}{c}45.8 \\
(13.1)\end{array}$ & $\begin{array}{c}40.3 \\
(15.4)\end{array}$ & 0.9 & 0.338 \\
\hline 발생 표준시간(\%)
\end{tabular}

${ }^{*} \alpha=0.05$ 에서 유의

\section{2 우회전 완료시간 및 시작점과 완료점 속도}

교차로 우회전 완료시간 측면에서 고령자와 청년운전자는 유의한 차이를 보였다 $\left(F_{1,24}=11.3, p=0.003\right)$. 고령운전자 의 평균 교차로 우회전 완료시간은 5.5(SD 1.2)초인 반면, 청년운전자는 $3.8(\mathrm{SD} 1.3$ ) 초로 고령운전자는 청년운전자 보 다 평균 약 2초 정도 우회전을 늦게 수행하였다(그림 3).

이는 고령자와 청년 운자자의 우회전 시작점과 완료점의 속도 차이와 관련되어 있었다. 고령운전자의 우회전 시작점 속도는 평균 $22.2(\mathrm{SD} 7.5) \mathrm{km} / \mathrm{h}$ 로 청년운전자의 평균 우회 전 시작점 속도인 $34.7(\mathrm{SD} 14.8) \mathrm{km} / \mathrm{h}$ 보다 약 $12 \mathrm{~km} / \mathrm{h}$ 정도 느렸다(그림 4). 또한 고령운전자의 우회전 완료점 속 도는 평균 23.8 (SD 5.6) km/h로 청년운전자의 평균 우회전 완료점 속도인 $32.2(\mathrm{SD} 9.1) \mathrm{km} / \mathrm{h}$ 보다 약 $9 \mathrm{~km} / \mathrm{h}$ 정도 느 렸다(그림 5). 


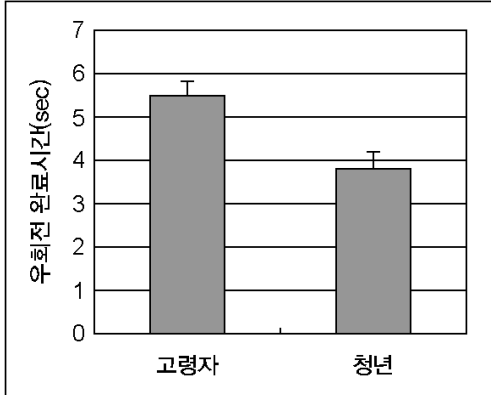

그림 3. 고령운전자와 청년층 우회전 완료시간

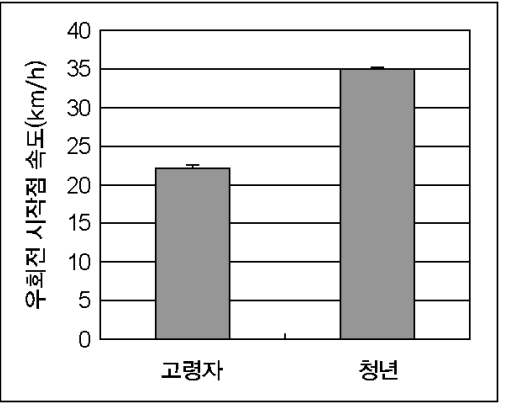

그림 4. 고령운전자와 청년층 우회전 시작점 속도

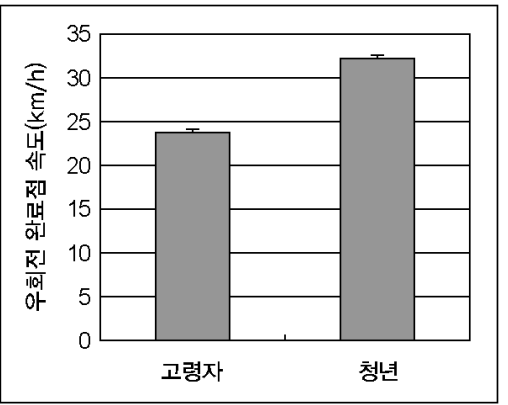

그림 5. 고령운전자와 청년층 우회전 완료점 속도

\section{3 운전대 각도}

우회전 진입시 운전대 각도 $\left(F_{1,24}<0.001, p=0.9\right)$, 최대 운전대 각도 $\left(F_{1,24}=0.93, p=0.35\right)$ 는 고령운전자와 청년운 전자 간에 유의한 차이를 보이지 않았다. 그러나, 우회전 완 료시 운전대 각도의 경우 고령운전자는 우회전 완료시 운전 대 각도를 평균 $60^{\circ}(\mathrm{SD} 30.5)$ 로 유지한 반면, 청년운전자 는 $100^{\circ}(\mathrm{SD} 45.1)$ 로 유지하여 약 $40^{\circ}$ 의 유의한 차이를 보였다 $\left(F_{1,24}=6.9, p=0.01\right)$. 즉, 고령운전자는 우회전 구간 완료지점에서 청년층보다 운전대를 원상태(0도)로 복원하는 경향이 높았다(그림 6).

또한 운전대 각도 변화의 매끄러움(smoothness)를 나타
내는 정규화 jerk의 값은 청년층보다 고령운전자의 경우가 유의하게 컸다 $\left(F_{1,24}=7.18, p=0.01\right)$. 이는 청년층의 우회 운전대 각도 변화 곡선이 매끄럽게 이어진 반면, 고령자의 운전대 각도 변화 곡선은 거침을 나타낸다(그림 7).

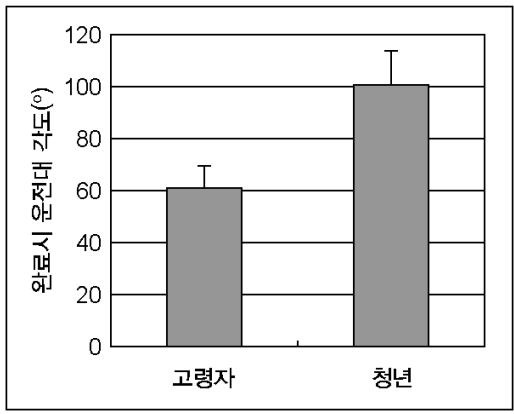

그림 6. 고령운전자와 청년층 우회전 완료시 운전대 각도

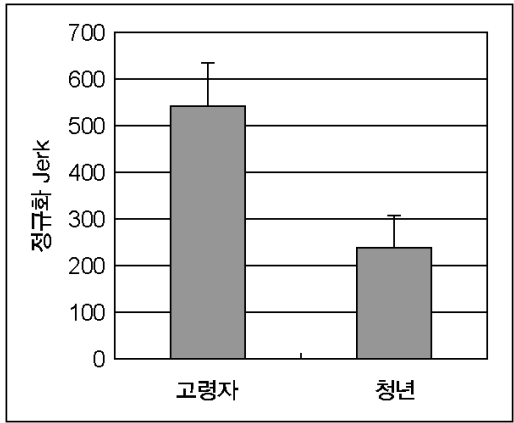

그림 7. 고령운전자와 청년층 운전대 각도의 정규화 jerk

\section{4 운전대 각속도}

고령운전자와 청년운전자의 운전대 최대 회전 각속도 발 생 표준시간은 통계적으로 유의한 차이를 보이지 않았다 $\left(F_{1,24}=0.95, p=0.34\right)$. 또한, 고령자와 청년층의 최대 운 전대 회전 각속도도 유의한 차이를 보이지 않았다 $\left(F_{1,24}=\right.$ $0.4, p=0.53)$. 고령운전자의 운전대 최대 각속도 평균은 $145 \% \mathrm{sec}(\mathrm{SD} 60)$ 이고, 청년운전자의 운전대 최대 각속도 평균은 $162 \% \mathrm{sec}(\mathrm{SD} 75.7$ )였으나, 통계적으로 유의하지 않았다.

\section{4. 토의 및 결론}

본 연구는 교차로 우회전을 위한 고령운전자의 운전대 조 작의 특성이 $\mathrm{Yan}(2000)$ 의 목적지향적 선형 팔 운동과 비 
슷함을 확인하였다. 본 연구에서 고령운전자의 교차로 우회 전을 위한 운전대 회전 조작 수행시간은 청년운전자 보다 2초 정도 길었고, 고령자의 우회전 시작점과 완료점 속도도 청년층보다 약 $10 \mathrm{~km} / \mathrm{h}$ 정도 느렸다. 또한, 고령자의 운전 대 조작에 대한 정규화 jerk가 청년층 보다 유의하게 컸다. 이는 청년층은 우회전을 위한 운전대 조작을 부드럽게 하지 만, 고령자는 운전대 조작 중 지속적으로 수정을 가함을 의 미한다. 이러한 특성은 $\operatorname{Yan}(2000)$ 의 목적지향적 선형 팔 운동에서도 나타난 특성으로 고령자의 목적지향적 팔 운동 능력에서 나타난 저하가 우회전을 위한 운전대 조작에서도 나타남을 확인할 수 있다.

본 연구에서 파악된 우회전에서의 고령자 운전대 조작 특 성은 직선 구간에서의 운전대 조작 특성과 달랐다. 본 연구 에서 고령운전자의 동작 정규화 jerk는 청년운전자 보다 커 고령운전자는 우회전 구간에서 운전대를 매끄럽게 조작하지 못하고 지속적으로 수정하는 경향을 보였다. 반면, Perryman \& Fitten(1996)는 고령운전자가 직선 주행 조건에서 청년 운전자보다 운전대를 보다 적은 빈도로 조작한다고 보고하 였다. 그러나 두 연구의 실험 조건이 다르므로 정확한 분석 으로 위해서는 직선 구간과 회전 구간에서의 운전대 조작 특성에 대한 비교 연구가 필요할 것이다.

Perryman \& Fitten(1996)에서 밝혀진 고령운전자 직선 도로 주행의 특징인 느린 주행 속도는 본 연구의 우회전 주 행에도 같이 나타났다. 본 연구의 실험에서 고령운전자는 청 년층보다 약 $10 \mathrm{~km} / \mathrm{h}$ 느리게 우회전을 진입하였고 또한 통 과하였다. 따라서 고령운전자는 회전 구간과 직선 구간에서 모두 청년운전자 보다 느리게 운전함을 알 수 있다.

고령운전자의 우회전 완료점에서 운전대 회전 각도가 청 년층 보다 작은 것은 고령자의 보수적 운전 특성과 관련지 을 수 있다. 고령운전자는 자신의 운동 수행 능력의 저하를 알고 있으며 이를 보상하기 위해 보다 안정적으로 운전하는 경향을 보인다(McGwin \& Brown, 1999). 또한 교차로 우 회전에서 고령자의 수행 완료시간이 길고, 우회전 완료시 운 전대를 원위치 상태로 복원하는 경향이 높은 것은 고령자의 안정적이고 보수적인 운전 특성을 나타내는 결과이다. 교차 로 회전에서 고령자가 청년운전자 보다 긴 수행시간을 보이 는 것은 교차로 좌회전에서도 나타나는 특성이다(Keskinen et al., 1998).

본 연구의 교차로 우회전에서 나타난 고령운전자의 안정 적이고 보수적인 운전 특성은 교차로에서의 고령운전자 사 고와 관련성이 적은 것으로 볼 수 있다. 본 연구에서 파악된 교차로 우회전시 고령운전자의 보수적이고 안정적인 운전 특성은 신체 노화에 따른 운동 계획과 수행 측면의 저하 특 성이다. 운동 수행 저하에 따른 고령운전자의 안정적인 우 회전 주행에도 불구하고 교차로에서 고령자의 운전사고가
많은 원인은 교차로의 복잡한 상황을 지각하고 판단하는 고 령자의 인지적 저하와 관련성이 높다고 볼 수 있다. 따라서 운동 계획과 수행에서 나타나는 고령자의 기능 저하는 고령 자의 높은 교차로 교통사고율의 주요 요인이 되지 않는다고 사료된다.

본 연구에서 도출된 고령운전자의 운동학적 운전 특성을 나타내는 변수들은 고령자의 운전 능력 수준을 파악하는데 이용될 수 있을 것이다. 본 연구에서 고령자의 교차로 운전 특성을 유의하게 나타내는 변수로 우회전 완료시간, 우회전 시작점과 완료점 속도, 완료시 운전대 각도 그리고 정규화 jerk(동작의 매끄러움)이 도출되었다. 따라서 본 연구에서 도출된 변수들을 활용하여 노화에 따른 운전 능력 저하의 세부 수준을 결정한다면 운동학적 측면에서 고령자 운전 능 력의 정도를 판정하는데 도움이 될 것이다.

본 연구는 시내 교차로 우회전에서 고령운전자와 청년운 전자의 평상시 주행 특성을 운전 시뮬레이터로 실험적으로 파악한 것으로 다음과 같은 결론을 도출할 수 있다. 첫째, 청년운전자는 교차로 진입 초기부터 빠르게 진입하고 계획 에 대한 수정이 적으며 우회전 완료시간이 빨랐다. 둘째, 고 령운전자는 회전 계획에 대한 수정이 지속적으로 나타나며, 우회전 완료시간이 느렸다. 셋째, 우회전 완료시점에서 고령 자의 운전대 회전 각도는 청년층보다 작아 운전대를 제자리 에 두어 안정적으로 운전하는 경향이 높았다.

그러나, 본 연구는 평상시 우회전 주행 특성을 파악하기 위해 우회전 진입 속도를 통제하지 않아 분석 결과들간의 관련성이 높다. 따라서 고령자의 우회전 운전 특성이 진입 속도에 따라 어떻게 달라지는지 파악하는 것도 분석할 필요 가 있다. 우회전 진입 속도에 따라, 우회전 완료시간, 우회전 완료점 속도, 완료시 운전대 각도에서 고령운전자와 청년운 전자간에 차이가 있는지 파악하는 것도 중요한 연구 주제가 될 것이다.

\section{Acknowledgements}

본 논문은 2007년도 과학기술부의 재원으로 한국과학재 단의 지원(R01-2007-000-20070-0)을 받아 수행되었 습니다.

\section{References}

경찰청, 2006년판 교통사고통계, 경찰청, 서울, 2006. 
경찰청, 2007 년판 교통사고통계, 경찰청, 서울, 2007.

경찰청, 2008 년판 교통사고통계, 경찰청, 서울, 2008.

도로교통안전공단, 교통사고 통계분석, 도로교통안전공단, 서울, 2004.

이준범, 김비아, 이세원, 운전수행에서 판단에 미치는 연령의 효과: 운전 시뮬레이션 연구, 한국안전학회지, 23(2), 45-50, 2008.

통계청, 한국통계연감, 통계청, 서울, 2001.

Bao, S. and Boyle, L. N., Age-related differences in visual scannning at median-divied highway intersections in rural areas, Accident Analysis and Prevention, 41, 146-152, 2009.

Guerrier, J. H., Manivannan, P., Pacheco, A. and Wilke, F. L., The relationship of age and cognitive characteristics of drivers to performance of driving tasks on an interactive driving simulator, Proceedings of the Human Factors and Ergonomics Society 39th annual meeting, 172 $-176,1995$.

Hong, S. H., Min, S. Y., Kim, B., Min, Y. K., Kang, J. K. and Min, B. C., Difference of driving performance according to turn types at the intersection and age, Proceeding of the 2009 IEEE International conference on Mechatronics and Automation, 2009.

Keskinen, E., Ota, H. and Katila, A., Older drivers fall in intersections: speed discrepancies between older driver and younger male drivers, Accident analysis and prevention, 30(3), 323-330, 1998.

Mayhew, D., Simpson, H. and Ferguson, S., Collisions involving senior drivers: High-risk conditions and location, Traffic injury prevention, 7(2), 117-124, 2006

McGwin, G. and Brown, D. B., Characteristics of traffic crashes among young, middle-aged and older drivers, Accident Analysis and Prevention, 31(3), 181-198, 1999.

Perryman, K. M. and Fitten, L. J., Effects of normal aging on the performance of motor-vehicle operational skills, Journal of geriatric psychiatry and neurology, 9(3), 136-141, 1996.

Teulings, H. L., Contreras-Vidal, J. L. and Stelmach, G. E., Parkinsonism reduces coordination of fingers, wrist, and arm in the fine motor control, Experimental Neurology, 146, 159-170, 1997.

Verhaegen, P. K., Toebat, K. L. and Delbeke, L. L., Safety of older drivers
- A study of their over-involvement ratio, Proceedings of the Human Factors and Ergonomics Society 32nd annual meeting, 1988

Yan, X., Radwan, E. and Guo, D., Effects of major-road vehicle speed and driver age and gender on left-turn gap acceptance, Accident Analysis and Prevention, 39(4), 843-852, 2007.

Yan, J. H., Effects of aging on linear and curvilinear aiming arm movements, Experimental Aging Research, 26, 393-407, 2000.

\section{Author listings}

Taebeum Ryu: bryu@hanbat.ac.kr

Highest degree: $\mathrm{Ph} . \mathrm{D}$. Department of Industrial and Management Engineering, POSTECH

Position title: Assistant Professor, Department of Industrial and Management Engineering, Hanbat National University

Areas of interest: Motion Analysis, Gerontechnology, UX Design

Byung Chan Min: bcmin@hanbat.ac.kr

Highest degree: Ph.D., Department of System Engineering. The University Electro-Communications(UEC) in Tokyo Position title: Associate Professor, Department of Industrial and Management Engineering, Hanbat National University Areas of interest: User Interface, Wealfare Engineering, Biosignal Processing

Date Received : 2010-03-10

Date Revised :2010-12-01

Date Accepted : 2010-12-01 